\title{
Acupuncture points and cutaneous perforating vessels identified with thermography
}

\author{
Soares Parreira F. ${ }^{1}$ Pereira Barbosa M. ${ }^{1} \quad$ Álvarez Prats D. ${ }^{1} \quad$ Carvajal Fernández O. ${ }^{1}$ \\ ${ }^{1}$ Clínica FisioOn, Fisioterapia Saúde Integral, Santa Maria da Feira, \\ Portugal \\ Rev Fisioter Invasiva 2019;2:112.
}

\begin{abstract}
Keywords

- Acupuncture

- acupuncture points

- perforating cutaneous vessel

- infrared thermography.

Aim To confirm the presence of perforating cutaneous vessels (PCV) in different acupuncture points (AP) in the upper limb using thermography.

Material and Methods A cross-sectional analytic study in the upper limb of voluntary subjects $(n=7)$. In total, 91 AP were analyzed, as well as 91 control points $(C P)$, one per each AP. In each subject, first the AP and corresponding CP were marked, and in second place, the real and thermographic images were captured. In the real images, the AP and $\mathrm{CP}$ were marked with circles. Thereafter, software was used to fuse the real image with the AP and the $\mathrm{CP}$ and the thermographic image with the PCV to observe the presence or lack of the same in the AP and CP.

Results When all the AP and CP were analyzed globally, significant differences were observed among these regarding the proportion of points which coincided with PCV ( $p$ 0.001 ). It is possible to verify that in the AP, the percentage of coincidence with PCV is $68.1 \%$ and in the control points this is $41.8 \%$. This relationship is demonstrated by the risk ratio and odds ratio values and the confidence intervals $(95 \% \mathrm{Cl})$. Thus, it was verified that in AP the probability (risk) of coincidence with PCV is $1.63[1.23 ; 2.16]$ times greater to the probability in the CP. In the same manner, due to the odds ratio, it is still possible to observe that in the AP the chance (odds) of coincidence with PCV is $2.98[1.63 ; 5.47]$ times greater to the CP. It is also shown that for the AP the likelihood of coinciding with perforating vessels is $7.50[1.31 ; 43.03]$ times greater compared to coinciding with $\mathrm{CP}$.

Discussion The presence of PCV in the area of AP must be treated with greater care, both due to the physiology of the same as well as its importance in clinical medicine. Although the precise location of the PCV varies, thermography is a useful tool to evaluate a patient and subsequently apply treatment.

Conclusions Overall, a strong statistical difference was found regarding the presence of PCV in the location of AP in the upper limb.
\end{abstract}

DOI https://doi.org/

$10.1055 / \mathrm{s}-0039-3401883$.

ISSN 2386-4591.
Copyright $\odot 2019$ by Thieme Revinter

Publicações Ltda, Rio de Janeiro, Brazil
License terms

$\circledast(1) \Theta \circledast$ 